\title{
Conhecimento e percepção de estudantes de medicina sobre abortamento legal
}

\author{
Nathália Maria Fonseca Fróes ${ }^{1}$, Cláudia Bacelar Batista ${ }^{1}$
}

1. Universidade Federal da Bahia, Salvador/BA, Brasil.

\begin{abstract}
Resumo
O abortamento é prática frequente no Brasil e importante causa de mortalidade materna. Mesmo em condições legais, as mulheres enfrentam diversas barreiras para acessar o procedimento, muitas vezes em decorrência do desconhecimento de médicos acerca dos marcos regulatórios. Este artigo objetiva avaliar o conhecimento de estudantes da Faculdade de Medicina da Bahia da Universidade Federal da Bahia sobre as leis que permitem o aborto no Brasil, bem como a percepção desses estudantes sobre o tema. Trata-se de estudo de corte transversal com análise qualitativa de dados obtidos pela aplicação de questionário a 237 estudantes. Apesar de os participantes demonstrarem conhecimento teórico adequado dos aspectos legais, houve incongruências e erros quando questionados sobre aplicação das leis em situações práticas de atendimento ao aborto legal. Os resultados demonstram a necessidade de fortalecer a abordagem do tema durante a graduação, de modo multidisciplinar e transversal. Vale ressaltar, por fim, que se observou entre os participantes inclinação favorável à descriminalização do aborto. Palavras-chave: Aborto legal. Estudantes de medicina. Conhecimento. Legislação. Saúde pública.
\end{abstract}

\section{Resumen}

\section{Conocimiento y percepción de estudiantes de medicina sobre el aborto legal}

El aborto es una práctica frecuente en Brasil y una importante causa de mortalidad materna. Incluso cuando cumplen con las condiciones legales, las mujeres enfrentan varias barreras para acceder al procedimiento, a menudo debido a la falta de conocimiento de los médicos sobre los marcos regulatorios. Este artículo tiene como objetivo evaluar el conocimiento de los estudiantes de la Facultad de Medicina de la Universidad Federal de Bahía sobre las leyes que permiten el aborto en Brasil, así como la percepción de estos estudiantes sobre el tema. Se trata de un estudio transversal con análisis cualitativo de datos obtenidos mediante la aplicación de un cuestionario a 237 alumnos. Si bien los participantes demostraron un conocimiento teórico adecuado de los aspectos legales, hubo inconsistencias y errores cuando se les preguntó sobre la aplicación de las leyes en situaciones prácticas de atención al aborto legal. Los resultados demuestran la necesidad de fortalecer la enseñanza de la temática durante la graduación, de manera multidisciplinar y transversal. Finalmente, cabe mencionar que los participantes mostraron una inclinación favorable hacia la despenalización del aborto.

Palabras clave: Aborto legal. Estudiantes de medicina. Conocimiento. Legislación. Salud pública.

\section{Abstract}

\section{Knowledge and perception of medical students on legal abortion}

Abortion is a frequent practice in Brazil and a major cause of maternal mortality. Even under legal conditions, women face many barriers to access the procedure, often related to physicians' unfamiliarity with the legislation. This article assess the knowledge of medical students from Faculdade de Medicina da Bahia of Universidade Federal da Bahia about the laws that regulate abortion in Brazil and their perception on the topic. This qualitative cross-sectional study analyzed data collected from a questionnaire answered by 237 students. Although the participants showed adequate theoretical knowledge of legal aspects, discrepant and incorrect answers were observed when asked about law enforcement in situations of legal abortion care, showing that education focused on the topic is required using multidisciplinary and transversal discussions during the medical course. Finally, we observed that participants tended to favor decriminalization of abortion.

Keywords: Abortion, legal. Students, medical. Knowledge. Legislation. Public health. 
Embora tratados como sinônimos pela literatura técnica, "abortamento" corresponde à interrupção da gestação até a $20^{\mathrm{a}}$ ou $22^{\mathrm{a}}$ semana com produto de peso inferior a $500 \mathrm{~g}$, enquanto "aborto" é o resultado do abortamento ${ }^{1}$. Prática frequente no país, o abortamento tem grande impacto sobre a saúde das mulheres brasileiras e é causa importante de mortalidade materna ${ }^{2}$.

Devido à subnotificação, é difícil estabelecer a real magnitude da morbimortalidade materna decorrente de abortamento ilegal no Brasil ${ }^{3}$. Em geral, estudos utilizam dados secundários de repositórios do Sistema Único de Saúde (SUS), como o Sistema de Informações Hospitalares (SIH/SUS), o Sistema de Informações sobre Nascidos Vivos, o Departamento de Informática do SUS e o Sistema de Informação sobre Mortalidade (SIM). Mesmo com essas limitações, estima-se que ocorram no Brasil, por ano, mais de 1 milhão de abortamentos provocados ${ }^{1}$.

Em 2011, o SIM registrou 77 óbitos maternos associados a aborto, o equivalente a 4,8\% do total de óbitos maternos ocorridos naquele ano ${ }^{3}$. Como a mortalidade corresponde a apenas uma face da situação, os dados de internação corroboram a magnitude do problema. Estudo que analisou registros obtidos no SIH/SUS referentes ao período de 1996 a 2012 aponta dados alarmantes ${ }^{4}$. A curetagem em pacientes que chegam em processo de abortamento é o segundo procedimento obstétrico mais realizado na rede pública de saúde. Nesse período, houve aproximadamente $240 \mathrm{mil}$ internações por complicações decorrentes do aborto por ano, gerando ao SUS custo anual de cerca de R\$ 45 milhões. Além disso, o coeficiente médio de aborto inseguro correspondeu a 17 ocorrências para mil mulheres em idade fértil, à razão de 33,2 abortos para cem nascidos vivos ${ }^{4}$. Pesquisa realizada no estado de Pernambuco teve resultados semelhantes, encontrando média anual de abortos inseguros equivalente a $36,1 \%$ do total de nascidos vivos ${ }^{5}$.

Dada sua magnitude, a morbimortalidade que acarreta e o alto custo sobre o SUS, o aborto deve ser visto e tratado como problema de saúde pública ${ }^{6}$. Quando realizado em condições precárias e sem assistência profissional adequada, o procedimento é chamado "aborto inseguro", com maior taxa de óbitos e complicações. A realização do procedimento por terceiro que não seja profissional de saúde capacitado é fator de risco para lesões físicas iatrogênicas, como perfurações de útero e anexos, infecções e hemorragias. Outro risco importante é o possível agravo da saúde psíquica da mulher durante todas as etapas do procedimento ${ }^{7}$.

Já o aborto seguro é praticado legalmente, em serviço de saúde estruturado, com equipe multiprofissional capacitada que oferte à mulher toda a atenção necessária ${ }^{4}$. O Código Penal brasileiro considera, em seu artigo 124, crime contra a vida provocar aborto em si mesma ou consentir que outrem Iho provoque ${ }^{8}$, especificando as penalizações até o artigo 127. Já o artigo 128 isenta de pena o aborto necessário - quando é a única opção para salvar a vida da mulher ou quando a gestação decorre de estupro, desde que a mulher deseje se submeter ao procedimento e este seja realizado por médico ${ }^{8}$.

Segundo Anjos e colaboradores ${ }^{6}$, em 2012 o Supremo Tribunal Federal decidiu que mulheres com fetos anencefálicos também têm direito a abortar. O Conselho Federal de Medicina ${ }^{9}$ publicou na época resolução em que descreveu o diagnóstico de anencefalia para esses casos de antecipação terapêutica do parto. Contudo, os abortamentos por malformações incompatíveis com a vida ainda não estão garantidos por lei. Desde a década de 1980, mulheres têm recorrido à Justiça brasileira para obter o direito de abortar nesses casos, sendo autorizadas a seguir com o procedimento na maioria das vezes ${ }^{10}$.

Em 2013, segundo Balogh ${ }^{11}$, o Conselho Federal de Medicina encaminhou proposta à comissão do Congresso Nacional responsável por avaliar a reforma do Código Penal, em que defendeu a autonomia da mulher para decidir se deseja ou não prosseguir com a gestação até a $12^{\mathrm{a}}$ semana. Até hoje, no entanto, a proposta segue fora de pauta na instância legislativa.

Na prática, hospitais tendem a fazer o procedimento quando a gestante corre risco de morte, mas o mesmo não ocorre em caso de aborto por violência sexual ${ }^{12}$. Ainda é comum que vítimas de estupro sofram violência institucional, manifestada na demora para atender ou na recusa de acolhimento, no acesso dificultado ou até mesmo em atos de discriminação explícita ${ }^{4}$. Além disso, por não estarem cientes de seus direitos ou não conhecerem as instituições que oferecem atendimento, muitas dessas mulheres sequer chegam ao serviço ${ }^{13}$. 
Estudo sobre experiências de aborto constatou que a relação com a equipe de saúde se baseia em desconfiança e receio de maus-tratos. Esse imaginário retarda a procura de assistência médica e gera tensão durante o internamento ${ }^{14}$. Outro estudo identificou alguns dos motivos para a baixa demanda pelo abortamento legal: contracepção de emergência conseguida pelas próprias vítimas; desconhecimento de instituições públicas que oferecem o serviço em situações legais; e subnotificação da violência sexual por entraves culturais e institucionais ${ }^{15}$.

A negação de atendimento à vítima de violência sexual é vista como omissão, e o médico pode ser penalizado civil e criminalmente por morte ou danos físicos e psicológicos gerados na vítima, conforme artigo 135 do Código Penal ${ }^{8,13}$. Em gestação decorrente de estupro, compete à equipe de saúde informar a mulher sobre o direito de interromper a gravidez, identificar seu desejo de fazê-lo e esclarecê-la, quando a decisão é levar a gestação a termo, sobre acompanhamento pré-natal, possibilidade de permanecer com a criança ou entregá-la para adoção etc. ${ }^{13}$

Vale ressaltar, no entanto, que o médico pode alegar objeção de consciência para se negar a realizar o procedimento. Trata-se de dispositivo criado a fim de preservar a integridade do profissional em casos de conflito moral, permitindo-Ihe não participar de procedimentos que considere contrários a seus valores. Esse direito, porém, não é reconhecido quando não há outro médico disponível para realizar o procedimento, ou quando há risco de morte ou danos à saúde da gestante em decorrência da omissão ${ }^{16,17}$. No momento imediatamente posterior à violência, dados os graves riscos à saúde da mulher, o médico não poderá utilizar desse dispositivo, tampouco exigir documento policial, como boletim de ocorrência ou laudo do Instituto Médico Legal. Por não terem embasamento legal, tais exigências podem configurar conduta ilícita e antiética ${ }^{13}$.

O Código Penal ${ }^{8}$ não exige qualquer documento para abortamento no caso de violência sexual, pois a vítima não tem obrigação legal de denunciar o crime à polícia, e sua afirmação tem presunção de veracidade, não cabendo ao médico contestá-la ${ }^{13}$. A Portaria 1.508/2005 do Ministério da Saúde ${ }^{18}$ determinou os chamados "Procedimentos de Justificação e Autorização da Interrupção da Gravidez", cinco termos que devem ser utilizados no serviço em casos de abortamento de gestações decorrentes de estupro ${ }^{13}$. O médico não deverá temer judicialização caso depois se revele que a gestação não foi fruto de violência sexual, pois é protegido pelo artigo 20 do Código Penal ${ }^{8}$. Se o serviço seguiu as cautelas procedimentais, apenas a mulher responderá criminalmente ${ }^{13}$, com pena prevista de um a três anos de reclusão.

É importante ressaltar que, de acordo com o artigo 154 do Código Penal ${ }^{8}$, ao médico é vedado revelar, sem justa causa, qualquer dado de que teve conhecimento durante a prática de sua profissão e que venha a causar danos a alguém. Isso significa que manter sigilo sobre aborto induzido é dever ético e legal, não cabendo ao profissional denunciar a paciente às autoridades. A inobservância dessa regra pode levar o médico a responder processos criminais e ético-profissionais pelos danos causados à mulher ${ }^{1,8,9}$.

O desconhecimento da legislação sobre aborto pode predispor o médico a agir de modo inadequado, colocando em risco a saúde da mulher. A situação ainda se agrava quando o profissional teme ser julgado moralmente ou sofrer processo penal ${ }^{19}$. Por isso, e por ser problema de saúde pública, além de direito previsto em lei, é relevante discutir a legislação sobre o tema nas escolas médicas, assim como aspectos éticos e legais e sua aplicação prática ${ }^{20}$.

O objetivo deste estudo é justamente avaliar o conhecimento e a percepção de estudantes de medicina sobre a legislação brasileira referente ao aborto. Acredita-se que os resultados podem contribuir com estratégias para ampliar o ensino sobre o tema, de modo a promover a consciência ética do profissional e o atendimento humanizado, de qualidade, para as mulheres que passam por esse delicado e difícil processo.

\section{Método}

Trata-se de estudo qualitativo, descritivo, de corte transversal, com amostragem não probabilística. Estudantes de todos os semestres da Faculdade de Medicina da Bahia da Universidade Federal da Bahia (FMB-UFBA) responderam voluntariamente a questionário estruturado e autoaplicável. $O$ instrumento foi produzido na ferramenta Formulários Google e enviado por correio 
eletrônico a todos os estudantes matriculados no segundo semestre letivo de 2017. Foram feitos quatro envios, com intervalo mínimo de sete dias entre eles, no período de janeiro a março de 2018.

Os questionários poderiam ser respondidos a qualquer hora e no ambiente de escolha do entrevistado, com duração média de 20 minutos. No corpo do e-mail estava o termo de consentimento livre e esclarecido e, caso concordasse em participar da pesquisa, o estudante poderia acessar o link com as questões. Com o propósito de manter a confidencialidade, não se pedia ao respondente que se identificasse no questionário.

Não foi realizado cálculo amostral, uma vez que o questionário foi entregue a todos os estudantes da FMB-UFBA. A amostra contou com 237 estudantes que aceitaram responder ao questionário. Como havia 1.022 alunos com matrícula ativa no segundo semestre letivo de 2017, a amostra correspondeu a $23,2 \%$ da população total. Dos 237 participantes, $16(6,8 \%)$ cursavam o $1^{\circ}$ semestre; 38 (16\%), o $2^{\circ}$ semestre; 11 (4,6\%), o $3^{\circ}$ semestre; 18 (7,6\%), o $4^{\circ}$ semestre; $17(7,2 \%)$, o $5^{\circ}$ semestre; 38 (16\%), o $6^{\circ}$ semestre; $16(6,8 \%)$, o $7^{\circ}$ semestre; $18(7,6 \%)$, o $8^{\circ}$ semestre; $23(9,7 \%)$, o $9^{\circ}$ semestre; 20 (8,4\%), o $10^{\circ}$ semestre; $7(3 \%)$, o $11^{\circ}$ semestre; $13(5,5 \%)$, o $12^{\circ}$ semestre; e outros $2(0,8 \%)$ não forneceram essa informação.

O questionário utilizado continha apenas questões objetivas e foi adaptado de dois estudos anteriores com médicos e outros profissionais de saúde ${ }^{20,21}$. No total, foram 22 questões divididas em quatro seções. A primeira seção coletou dados sociodemográficos, incluindo faixa etária, sexo, estado civil, religião, renda familiar e grupo racial. A segunda abordou os conhecimentos gerais dos estudantes sobre abortamento por meio de afirmações que deviam ser identificadas como verdadeiras ou falsas. Nessa mesma seção ainda se buscou identificar com quais componentes curriculares o aluno tivera contato em alguma atividade acadêmica sobre o tema. Já a terceira seção trouxe aspectos específicos da legislação sobre aborto no Brasil mediante perguntas fechadas e de múltipla escolha. Por fim, a quarta seção dedicou-se a conhecer a percepção do participante sobre abortamento. $\mathrm{O}$ instrumento de coleta de dados está disponível no Anexo deste artigo. Os dados foram organizados e analisados no software Microsoft Excel.

\section{Resultados}

\section{Caracterização sociodemográfica}

No total, 237 estudantes responderam ao questionário. A maioria era do sexo feminino $(61,2 \%)$, com entre 19 e 22 anos de idade (41,1\%), solteira (91,1\%), parda $(48,7 \%)$, com renda familiar entre 5 e 10 salários mínimos $(26,7 \%)$ e católica $(25 \%)$ ou sem religião (25\%). Estudantes de todos os semestres responderam ao questionário, com predominância dos que então cursavam o sexto semestre (16\%).

\section{Conhecimentos gerais sobre aborto}

A maioria dos estudantes classificou corretamente os enunciados sobre aborto. A Tabela 1 traz as assertivas com suas respectivas respostas corretas, acompanhadas do número absoluto e percentual de estudantes que assinalaram cada afirmação como "verdadeiro" ou "falso". Embora a maioria tenha acertado, muitos estudantes não sabiam que o aborto é responsável por grande parte das mortes maternas em países em desenvolvimento $(24,9 \%)$ e que procedimentos repetidos podem trazer riscos a uma futura gestação (30\%).

Sobre o perfil das mulheres que abortam, $21,1 \%$ dos estudantes responderam de forma equivocada que as mulheres que mais recorrem ao aborto provocado no Brasil costumam ter excedido o número desejado de filhos, e 23,2\% desconheciam que a maioria dessas mulheres é jovem. A maioria (87,8\%) concorda que o planejamento reprodutivo contribui para prevenir o aborto provocado. Quase todos os estudantes acreditam que o aborto é problema de saúde pública $(96,2 \%)$ e discordam que o acesso ao planejamento reprodutivo no Brasil seja adequado (98,3\%). Por fim, $62 \%$ dos estudantes consideraram que o aborto não deve ser utilizado como método de planejamento reprodutivo. 
Tabela 1. Conhecimentos gerais sobre aborto

\begin{tabular}{|c|c|c|c|c|}
\hline \multirow{2}{*}{ Assertivas } & \multicolumn{2}{|c|}{ Verdadeiro } & \multicolumn{2}{|c|}{ Falso } \\
\hline & $\mathbf{n}$ & $\%$ & $\mathbf{n}$ & $\%$ \\
\hline $\begin{array}{l}\text { Nos países em desenvolvimento, o aborto é responsável por grande parte das } \\
\text { mortes maternas. (V) }\end{array}$ & 178 & 75,1 & 59 & 24,9 \\
\hline $\begin{array}{l}\text { O aborto repetido por dilatação e curetagem pode trazer riscos a uma futura } \\
\text { gestação. (V) }\end{array}$ & 166 & 70,0 & 71 & 30,0 \\
\hline $\begin{array}{l}\text { As mulheres que mais recorrem ao aborto provocado no Brasil costumam ter } \\
\text { excedido o número desejado de filhos. }(\mathrm{F})\end{array}$ & 50 & 21,1 & 187 & 78,9 \\
\hline $\begin{array}{l}\text { A maioria das mulheres que mais recorrem ao aborto provocado no Brasil é } \\
\text { jovem. (V) }\end{array}$ & 182 & 76,8 & 55 & 23,2 \\
\hline $\begin{array}{l}\text { O acesso eficiente ao planejamento familiar contribui para prevenir o aborto } \\
\text { provocado. (V) }\end{array}$ & 208 & 87,8 & 29 & 12,2 \\
\hline O aborto é problema de saúde pública. (V) & 228 & 96,2 & 9 & 3,8 \\
\hline O acesso ao planejamento familiar promovido no Brasil é adequado. (F) & 4 & 1,7 & 233 & 98,3 \\
\hline O aborto não deve ser utilizado como método de planejamento familiar. (V) & 147 & 62,0 & 90 & 38 \\
\hline
\end{tabular}

V: verdadeiro; F: falso

\section{Conhecimento da legislação sobre aborto}

A Tabela 2 traz assertivas sobre aspectos jurídicos do aborto no Brasil com suas respectivas respostas corretas, e o número absoluto e percentual de estudantes que assinalaram cada afirmação como "verdadeiro" ou "falso". Sobre o estabelecido no Código Penal ${ }^{8}, 92 \%$ dos estudantes sabiam que o aborto praticado por médico não é punido quando a gestante corre risco de morte, 94,9\% acertaram que não há punição quando a gravidez resulta de estupro, e 91,1\% reconheceram que não há punição em casos de malformação cerebral incompatível com a vida extrauterina. Contudo, $28,3 \%$ dos estudantes desconheciam que o aborto é punido quando há risco para a saúde da gestante. Apenas 1,7\% dos estudantes achava que o aborto não era punido quando a gestante é menor de idade, assim como $0,8 \%$ nos casos em que a mulher não deseja ter o filho.

Quase a totalidade dos estudantes (98,3\%) sabia que o aborto legal dispensa consentimento do marido. Porcentagens menores sabiam que não é necessário boletim de ocorrência (80,3\%) ou laudo do Instituto Médico Legal (82,9\%). Quase $24 \%$ desconheciam o fato de que nenhum documento é necessário, bastando o depoimento da mulher.
Quanto à atitude do médico caso suspeite de abortamento ilegal, apenas $51,5 \%$ dos estudantes sabiam que, salvo por justa causa, não pode haver denúncia, e $89,6 \%$ tinham conhecimento de que não se deve denunciar à polícia; contudo, $38,5 \%$ acreditavam que não se deve denunciar de modo algum. Quanto ao registro da suspeita em prontuário, $69,9 \%$ dos entrevistados sabiam que o procedimento deve ser devidamente anotado para a correta condução do caso. No entanto, 27,5\% acreditavam erroneamente que a suspeita não deve constar no prontuário, pois a informação é sigilosa, e 4,2\% achavam que a anotação no prontuário deve ser feita para fundamentar a denúncia.

Sobre a objeção de consciência, $86,8 \%$ dos estudantes sabiam que se trata de um direito profissional, mas que não pode ser alegado em qualquer ocasião, e 74,8\% tinham ciência de que, em situação de abortamento juridicamente permitido, esse dispositivo não pode ser utilizado na ausência de outro médico que realize o procedimento. Todavia, apenas 30,3\% sabiam que o direito à objeção de consciência não cabe quando há complicações decorrentes de abortamento inseguro, assim como somente $50 \%$ sabiam que esse direito não pode ser alegado nos casos de necessidade de abortamento por risco iminente de morte da mulher. 
Tabela 2. Conhecimento da legislação sobre abortamento

\begin{tabular}{|c|c|c|c|c|}
\hline \multirow{2}{*}{ Assertivas } & \multicolumn{2}{|c|}{ Verdadeiro } & \multicolumn{2}{|c|}{ Falso } \\
\hline & $\mathbf{n}$ & $\%$ & $\mathbf{n}$ & $\%$ \\
\hline \multicolumn{5}{|c|}{$\begin{array}{l}\text { De acordo com o artigo } 128 \text { do Código Penal brasileiro e a decisão do Supremo Tribunal Federal de 2012, } \\
\text { não se pune o aborto praticado por médico quando: }\end{array}$} \\
\hline A gestante corre risco de morte. (V) & 218 & 92,0 & 19 & 8,0 \\
\hline A gravidez resulta de estupro. (V) & 225 & 94,9 & 12 & 5,1 \\
\hline A gestante é menor de idade. (F) & 4 & 1,7 & 233 & 98,3 \\
\hline A mulher não deseja ter o filho. (F) & 2 & 0,8 & 235 & 99,2 \\
\hline Há risco para a saúde da gestante. (F) & 67 & 28,3 & 170 & 71,7 \\
\hline $\begin{array}{l}\text { Em casos de feto com malformação cerebral incompatível com a vida } \\
\text { extrauterina. (V) }\end{array}$ & 216 & 91,1 & 21 & 8,9 \\
\hline \multicolumn{5}{|l|}{ Para que seja realizado o abortamento legal: ${ }^{* a}$} \\
\hline É necessário boletim de ocorrência. (F) & 46 & 19,7 & 188 & 80,3 \\
\hline É necessário laudo do Instituto Médico Legal. (F) & 40 & 17,1 & 194 & 82,9 \\
\hline É necessário consentimento do marido. (F) & 4 & 1,7 & 230 & 98,3 \\
\hline Nenhum documento é necessário, apenas a palavra da mulher. (V) & 178 & 76,1 & 56 & 23,9 \\
\hline \multicolumn{5}{|l|}{ Quando há suspeita de abortamento ilegal, o médico: ${ }^{\text {b }}$} \\
\hline Deve denunciar à polícia. $(\mathrm{F})$ & 24 & 10,4 & 207 & 89,6 \\
\hline Não deve denunciar de modo algum. (F) & 89 & 38,5 & 142 & 61,5 \\
\hline Não pode denunciar, salvo por justa causa. (V) & 119 & 51,5 & 112 & 48,5 \\
\hline \multicolumn{5}{|l|}{ A suspeita de abortamento ilegal deve ser anotada no prontuário? c } \\
\hline Sim, porque o registro é necessário à denúncia. (F) & 10 & 4,2 & 226 & 95,8 \\
\hline Não, porque é informação sigilosa. (F) & 65 & 27,5 & 171 & 72,5 \\
\hline Sim, porque o registro é necessário à correta condução do atendimento. (V) & 165 & 69,9 & 71 & 30,1 \\
\hline \multicolumn{5}{|l|}{ Sobre o direito à objeção de consciência: ${ }^{a}$} \\
\hline $\begin{array}{l}\text { Objeção de consciência é direito do profissional e pode ser alegado em } \\
\text { qualquer ocasião. (F) }\end{array}$ & 31 & 13,2 & 203 & 86,8 \\
\hline $\begin{array}{l}\text { O direito à objeção de consciência não cabe nos casos de necessidade de } \\
\text { abortamento por risco de morte para a mulher. (V) }\end{array}$ & 117 & 50,0 & 117 & 50,0 \\
\hline $\begin{array}{l}\text { O direito à objeção de consciência não cabe em situação de abortamento } \\
\text { juridicamente permitido na ausência de outro(a) médico(a) que o faça. (V) }\end{array}$ & 175 & 74,8 & 59 & 25,2 \\
\hline $\begin{array}{l}\text { O direito à objeção de consciência não cabe quando há complicações } \\
\text { decorrentes de abortamento inseguro. (V) }\end{array}$ & 71 & 30,3 & 163 & 69,7 \\
\hline
\end{tabular}

V: verdadeiro; F: falso; *algumas assertivas não foram avaliadas por todos os participantes; ${ }^{\mathrm{a}} 234$ respostas; ${ }^{\mathrm{b}} 231$ respostas; ${ }^{\mathrm{C}} 236$ respostas

\section{Percepção dos estudantes sobre aborto}

Grande parte dos estudantes se posicionou a favor do aborto provocado em diversas situações. A maioria é favorável nos casos previstos em lei estupro (93,7\%), risco de morte (92,8\%) e malformação incompatível com a vida $(91,1 \%)$. Porcentagens significativas apoiavam o procedimento quando há risco para a saúde (70,5\%), quando a mulher não deseja ter o filho $(69,2 \%)$, na vigência de dificuldades socioeconômicas $(60,3 \%)$, quando a gravidez ocorre na adolescência $(54,4 \%)$ e quando há malformação compatível com a vida (51,5\%). Apenas 2,5\% dos entrevistados disse ser contra o aborto provocado em qualquer situação.

$\mathrm{Na}$ opinião de $74,7 \%$ dos estudantes, a lei do aborto deveria ser mudada. Cerca de $65 \%$ acreditam que o aborto deve ser totalmente descriminalizado, enquanto $56,7 \%$ concordam que a lei deveria 
ampliar o conjunto de casos permitidos. No entanto, apenas $38,6 \%$ afirmaram que praticariam o ato profissionalmente em caso de descriminalização; $81,1 \%$ acham que os médicos que praticam abortamento ilegal não deveriam ser punidos; $85,8 \%$ não denunciariam médicos por tal prática; e $80,7 \%$ não consideram crime recomendar medicamento abortivo, desde que não haja prescrição por escrito.

Em situação hipotética na qual fosse solicitado a um obstetra realizar abortamento ilegal, 93,6\% concordam que o médico deve esclarecer o problema à paciente; $25,1 \%$ acreditam que o profissional deveria atender ao pedido; e 20,4\% afirmaram que o obstetra deveria tentar reverter o desejo da paciente. Apenas 5,5\% acham que o médico deveria recomendar outro profissional, e 5,1\% que o obstetra deveria indicar remédio abortivo.

Quando questionados sobre a possibilidade de atender caso de aborto quando formados, 94,5\% afirmaram que adotariam postura de aproximação perante as angústias da mulher. Nenhum estudante afirmou que sentiria raiva da paciente, mas $1,3 \%$ afirmou que reprovaria o ato, e $0,4 \%$ disse que manteria o mínimo de contato necessário. Por fim, $54,7 \%$ acreditam que a criminalização do aborto cria situações difíceis e delicadas para os médicos.

Para $81 \%$ dos estudantes, médicos que realizam abortamento legal deveriam ter qualificação específica; 57,9\% afirmam que atuariam em serviço de referência para aborto legal ou em qualquer outro que envolva o procedimento. Apenas 40,7\% sabem qual é o centro de referência para a prática do abortamento legal na cidade de Salvador/BA.

\section{Discussão}

\section{Conhecimentos gerais sobre aborto}

A maior parte dos estudantes demonstrou conhecimento geral satisfatório sobre o tema, acertando a maioria das afirmações propostas. O resultado foi semelhante ao encontrado em pesquisa com médicos assistentes de emergência em ginecologia e obstetrícia ${ }^{20}$. Os aspectos com maiores taxas de erro dizem respeito a impacto na mortalidade materna, complicações para uma futura gestação, perfil das mulheres que abortam e uso do aborto como forma de planejamento familiar. Isso demonstra déficit de conhecimento sobre a epidemiologia do aborto e seu impacto na saúde pública e na saúde das mulheres, além da perpetuação de estereótipos sobre a mulher que aborta.

\section{Conhecimento da legislação sobre aborto}

Os participantes demonstraram bom conhecimento sobre as situações permitidas por lei: mais de $90 \%$ acertaram quais são as três circunstâncias que não configuram crime. Revisão publicada em 2013 analisou estudos brasileiros publicados entre 2001 e 2011 sobre saberes e condutas de profissionais de saúde diante do aborto e encontrou também conhecimento adequado das situações legais ${ }^{22}$. Igual resultado foi aferido em estudo envolvendo acadêmicos de medicina no Rio Grande do Norte, com acerto superior a $90 \%{ }^{23}$. Entretanto, em pesquisa realizada em universidade pública do estado de São Paulo, só cerca da metade dos participantes acertou todas as questões referentes à temática ${ }^{19}$, e outro estudo sobre anencefalia com médicos de Goiânia identificou que apenas 44,3\% sabiam que o médico pode realizar a antecipação terapêutica do parto sem autorização do Estado ${ }^{24}$.

$\mathrm{Na}$ presente pesquisa, a maior taxa de erro encontrada esteve relacionada ao risco de saúde para a gestante, pois $28,3 \%$ dos estudantes acreditavam erroneamente que o aborto pode ser praticado neste caso sem punição. Outro estudo obteve resultado semelhante $(20,9 \%)^{23}$. Já o erro mais frequente citado pela literatura é a crença de que o procedimento é legal em caso de qualquer malformação grave do feto ${ }^{19,25}$. Tal engano ocorre provavelmente pelas frequentes autorizações judiciais nesses casos, mas, à exceção da anencefalia, essas situações não estão previstas em lei ${ }^{25}$. Essa concepção errônea pode não ter sido tão prevalente entre os estudantes do presente estudo devido à formulação da pergunta, que induzia ao acerto, pois o questionário elencava apenas malformações cerebrais incompatíveis com a vida extrauterina.

Quanto aos documentos que devem ser exigidos em casos de estupro, a maioria dos estudantes está ciente que não são necessários boletim de ocorrência ou laudo do Instituto Médico Legal. No entanto, parcela significativa $(23,9 \%)$ não sabia que o testemunho da mulher é suficiente. Este parece ser problema recorrente na formação médica, pois diversos estudos mostram impacto negativo na prática profissional decorrente de desconhecimento de preceitos legais ${ }^{20,25,26}$. Trabalho 
envolvendo estudantes também demonstrou falha neste conteúdo e destacou a pouca ênfase que o assunto recebe na formação médica ${ }^{19}$. Tal desconhecimento pode se traduzir em entraves no atendimento às pacientes.

Foram percebidas outras deficiências no conhecimento sobre normas do Código Penal ${ }^{8}$ brasileiro e do Código de Ética Médica ${ }^{16}$, destacando-se questões de sigilo, possibilidade de denúncia e registro em prontuário para casos de abortamento induzido. Essas falhas parecem ser comuns entre médicos ${ }^{22}$. Além disso, apesar de a maioria dos participantes da presente pesquisa conhecer as limitações da objeção de consciência, os estudantes tiveram dificuldade para identificar as situações práticas em que este direito não pode ser exercido.

De modo geral, observa-se que a população estudada conhece aspectos legais do aborto, o que não se reflete, contudo, quando os estudantes são questionados sobre a aplicação prática das leis. Em outras palavras, os entrevistados conhecem a legislação, mas não sabem quando e como aplicá-la. Esse resultado pode indicar falta de diálogo entre os componentes curriculares, ou seja, o conteúdo teórico aprendido nas disciplinas do eixo ético-humanístico não encontra ressonância ou não é reforçado nas disciplinas que tratam especificamente do treinamento para a prática médica. Ampliar a inserção da temática do aborto nos componentes curriculares das especialidades clínicas e cirúrgicas, na ginecologia e na obstetrícia, por meio de discussões sobre casos clínicos, situações-problema e, sobretudo, $\mathrm{o}$ atendimento às mulheres, pode auxiliar $\mathrm{a}$ formação adequada dos estudantes.

\section{Opiniões pessoais dos estudantes sobre aborto}

A maioria dos estudantes concorda com abortamento nas situações já previstas em lei, o que corrobora a opinião de médicos encontrada em outros estudos $^{22,25-27}$. Observou-se também postura favorável em outras circunstâncias: cerca de dois terços dos estudantes apoiam o aborto quando há risco para a saúde da gestante, quando a gravidez é indesejada e na vigência de dificuldades socioeconômicas. Pouco mais da metade concorda com o procedimento quando a gravidez ocorre na adolescência e quando há no feto malformação compatível com a vida.
Esse perfil contrastou com o de estudantes de faculdade privada, também sediada em Salvador/BA, cuja anuência foi de $27 \%$ para qualquer malformação e de $29,9 \%$ para interrupção voluntária da gravidez ${ }^{28}$. É possível que esse contraste se deva tanto a diferenças de perfil socioeconômico quanto de carga horária dedicada a ética médica. Cacique, Passini Junior e Osis ${ }^{22}$, em revisão de pesquisas com médicos, observaram resultados mais próximos, com dois estudos apontando aprovações de $61,4 \%$ e $47,4 \%$ para risco de saúde física da gestante e porcentagens inferiores a $50 \%$ para as demais situações.

Sobre a regulamentação, a maioria dos participantes da presente pesquisa acredita que a legislação deve sofrer mudanças, e aproximadamente dois terços creem que a prática deve ser totalmente descriminalizada. Mais de $80 \%$ dos estudantes considera que o médico que pratica abortamento ilegal não deveria ser punido, e afirmam ainda que não os denunciariam. Além disso, um em quatro estudantes acredita que, quando um aborto ilegal Ihe é solicitado, o profissional deve atender ao pedido.

Essa defesa da ampliação do direito ao aborto, assim como de conduta mais permissiva, difere dos dados encontrados na literatura ${ }^{20,25}$, podendo-se aventar aqui a existência de viés de seleção. Por se tratar de questão permeada de tabus e preconceitos, é possível que justamente aqueles estudantes com ideias mais liberais e que se interessam pela temática tenham se disposto a responder ao questionário.

Fato interessante é que, apesar do perfil mais permissivo, apenas $38,6 \%$ declararam que em sua futura prática profissional fariam o procedimento caso o aborto fosse descriminalizado, o que mostra certa contradição. Esta situação converge com a literatura, que reporta tendência de aumentar o número de alegações de objeção de consciên$\mathrm{cia}^{29}$. Pesquisa com estudantes de escolas médicas do Piauí mostrou elevadas taxas: $13,2 \%$ dos participantes negariam o serviço em caso de risco de morte para a gestante; $31,6 \%$ nos casos de anencefalia; e 50,8\% em gestações decorrentes de estupro ${ }^{29}$. O mais preocupante é que parte significativa desses estudantes não recomendaria outro médico para mulheres em busca de atendimento, nem as orientaria sobre todas as possibilidades para realizar o aborto. Os índices de objeção de consciência quase dobram em situação de 
estupro ${ }^{29}$. Esses resultados demonstram o impacto que a moral e as crenças pessoais do médico têm na saúde das mulheres, o que talvez explique a discrepância entre as opiniões dos estudantes e as projeções de prática futura - discrepância também evidenciada em outra pesquisa ${ }^{28}$.

Não se deve exigir do profissional que participe de práticas com as quais não concorda, mas o médico deve estar ciente do dever de assegurar e facilitar o acesso ao tratamento recusado. A objeção de consciência deve ser eticamente justificada, e não estratégia para esconder preconceitos ou medo de processos e linchamento moral. Tal dispositivo não pode ser entrave para que mulheres tenham acesso ao aborto ${ }^{29}$. Nesse sentido, chama atenção ainda que $57,9 \%$ dos entrevistados afirmaram que atuariam em serviço de referência para aborto, mas porcentagem notavelmente menor se disporia a realizar abortamento legal.

\section{Considerações finais}

Os participantes deste estudo demonstraram conhecer a legislação brasileira referente ao aborto, mas tiveram dificuldades em relacionar a lei com possíveis situações práticas. É necessário, portanto, abordar a questão de modo transversal e multidisciplinar, em relação com a prática clínica, reforçando atitudes exemplares de professores e preceptores a fim de que, para além do respeito à lei nos casos previstos, o acolhimento às mulheres que chegam ao serviço de saúde já com aborto em curso seja empático e solidário. Tal abordagem pode ajudar a formar profissionais mais bem preparados para efetivar os direitos reprodutivos da mulher, parte importante do cuidado integral à saúde da população feminina.

Por outro lado, foi possível perceber postura mais liberal e menos preconceituosa dos estudantes, talvez devido à educação ética oferecida pela faculdade, já que a instituição onde ocorreu a pesquisa oferta eixo ético-humanístico com oito componentes curriculares que tratam de questões de gênero, aborto e objeção de consciência, início da vida, direitos sexuais e reprodutivos, autonomia da mulher e auxílio à paciente na tomada de decisão sobre realizar ou não o aborto legal ${ }^{30}$.

A capacidade de compreender a magnitude e abrangência desse fenômeno social e pensar soluções depende de investimento em educação e informação, visando à formação crítica dos indivíduos. É preciso também comprometimento dos cidadãos e de setores diretamente envolvidos, como Estado e profissionais de saúde, sempre observando princípios basais como democracia, laicidade do Estado, igualdade de gênero e dignidade da pessoa humana. A atenção humanizada no processo de abortamento faz parte dos direitos reprodutivos e sexuais das mulheres, e assegurá-la é dever de todos os profissionais da saúde ${ }^{1}$.

\section{Referências}

1. Brasil. Ministério da Saúde. Norma técnica: atenção humanizada ao abortamento [Internet]. Brasília: Ministério da Saúde; 2005 [acesso 12 fev 2021]. Disponível: https://bit.ly/3d4exrH

2. Brasil. Ministério da Saúde. Saúde Brasil 2013: uma análise da situação de saúde e das doenças transmissíveis relacionadas à pobreza [Internet]. Brasília: Ministério da Saúde; 2014 [acesso 30 jan 2020]. Disponível: https://bit.ly/3d8Coqk

3. Adesse L, Silva KS, Bonan C, Fonseca VM. Complicações do abortamento e assistência em maternidade pública integrada ao Programa Nacional Rede Cegonha. Saúde Debate [Internet]. 2015 [acesso 21 jan 2020];39(106):694-706. DOI: 10.1590/0103-1104201510600030011

4. Martins-Melo FR, Lima MS, Alencar CH, Ramos AN Jr, Carvalho FHC, Machado MMT, Heukelbach J. Temporal trends and spatial distribution of unsafe abortion in Brazil, 1996-2012. Rev Saúde Pública [Internet]. 2014 [acesso 21 jan 2020];48(3):508-20. DOI: 10.1590/S0034-8910.2014048004878

5. Mello FMB, Sousa JL, Figueroa JN. Magnitude do aborto inseguro em Pernambuco, Brasil, 1996 a 2006. Cad Saúde Pública [Internet]. 2011 [acesso 21 jan 2020];27(1):87-93. DOI: 10.1590/S0102-311X2011000100009 
6. Anjos KF, Santos VC, Souzas R, Eugênio BG. Aborto e saúde pública no Brasil: reflexões sob a perspectiva dos direitos humanos. Saúde Debate [Internet]. 2013 [acesso 21 jan 2020];37(98):504-15. DOI: 10.1590/ S0103-11042013000300014

7. Sandi SF, Braz M. As mulheres brasileiras e o aborto: uma abordagem bioética na saúde pública. Rev. bioét. (Impr.) [Internet]. 2010 [acesso 21 jan 2020];18(1):131-53. Disponível: https://bit.ly/3jlon3C

8. Brasil. Decreto-Lei $n^{\circ} 2.848$, de 7 de dezembro de 1940. Código Penal. Diário Oficial da União [Internet]. Rio de Janeiro, p. 23911, 31 dez 1940 [acesso 30 jan 2020]. Seção 1. Disponível: https://bit.ly/3d8FTNe

9. Conselho Federal de Medicina. Resolução CFM n 1.989, de 10 de maio de 2012. Dispõe sobre o diagnóstico de anencefalia para a antecipação terapêutica do parto e dá outras providências. Diário Oficial da União [Internet]. Brasília, p. 308-9, 14 maio 2012 [acesso 30 jan 2020]. Seção 1. Disponível: https://bit.ly/3afMHXv

10. Diniz D. Aborto seletivo no Brasil e alvarás judiciais. Bioética [Internet]. 1997 [acesso 21 jan 2020];5(1):19-24. Disponível: https://bit.ly/3pfEhDV

11. Balogh H. Conselho Federal de Medicina apoia opção de aborto até o terceiro mês. Folha de S.Paulo [Internet]. 23 out 2014 [acesso 21 jan 2020]. Disponível: https://bit.ly/3pmNPNC

12. Duarte GA, Osis MJD, Faúndes A, Sousa MH. Aborto e legislação: opinião de magistrados e promotores de justiça brasileiros. Rev Saúde Pública [Internet]. 2010 [acesso 21 jan 2020];44(3):406-20. DOI: 10.1590/ S0034-89102010005000006

13. Brasil. Ministério da Saúde. Prevenção e tratamento dos agravos resultantes da violência sexual contra mulheres e adolescentes: norma técnica [Internet]. $3^{\text {a }}$ ed. Brasília: Ministério da Saúde; 2012 [acesso 30 jan 2020]. Disponível: https://bit.ly/3rPidSk

14. McCallum C, Menezes G, Reis AP. O dilema de uma prática: experiências de aborto em uma maternidade pública de Salvador, Bahia. Hist Ciênc Saúde Manguinhos [Internet]. 2016 [acesso 21 jan 2020];23(1):37-56. DOI: 10.1590/S0104-59702016000100004

15. Farias RS, Cavalcanti LF. Atuação diante das situações de aborto legal na perspectiva dos profissionais de saúde do Hospital Municipal Fernando Magalhães. Ciênc Saúde Colet [Internet]. 2012 [acesso 21 jan 2020];17(7):1755-63. DOI: 10.1590/S1413-81232012000700014

16. Conselho Federal de Medicina. Código de ética médica: Resolução CFM n 1.931, de 17 de setembro de 2009 [Internet]. Brasília: CFM; 2010 [acesso 30 jan 2020]. Disponível: https://bit.ly/3tOn4oJ

17. Diniz D. Objeção de consciência e aborto: direitos e deveres dos médicos na saúde pública. Rev Saúde Pública [Internet]. 2011 [acesso 21 jan 2020];45(5):981-5. DOI: 10.1590/S0034-89102011005000047

18. Brasil. Ministério da Saúde. Portaria $n^{\circ} 1.508$, de $1^{\circ}$ de setembro de 2005 . Dispõe sobre o Procedimento de Justificação e Autorização da Interrupção da Gravidez nos casos previstos em lei, no âmbito do Sistema Único de Saúde - SUS. Diário Oficial da União [Internet]. Brasília, nº 170, p. 124-5, 2 set 2005 [acesso 12 fev 2021]. Seção 1. Disponível: https://bit.ly/2ZfcPLK

19. Almeida MAS, Amorim FHR, Barbosa IAF, Dias A, Morita I. Legislação brasileira relativa ao aborto: o conhecimento na formação médica. Rev Bras Educ Méd [Internet]. 2012 [acesso 21 jan 2020];36(2):243-8. DOI: 10.1590/S0100-55022012000400013

20. Loureiro DC, Vieira EM. Aborto: conhecimento e opinião de médicos dos serviços de emergência de Ribeirão Preto, São Paulo, Brasil, sobre aspectos éticos e legais. Cad Saúde Pública [Internet]. 2004 [acesso 21 jan 2020];20(3):679-88. DOI: 10.1590/S0102-311X2004000300004

21. Rocha WB, Silva AC, Leite SML, Cunha T. Percepção de profissionais da saúde sobre abortamento legal. Rev. bioét. (Impr.) [Internet]. 2015 [acesso 21 jan 2020];23(2):387-99. DOI: 10.1590/1983-80422015232077

22. Cacique DB, Passini R Jr, Osis MJMD. Opiniões, conhecimento e atitudes de profissionais da saúde sobre o aborto induzido: uma revisão das pesquisas brasileiras publicadas entre 2001 e 2011. Saúde Soc [Internet]. 2013 [acesso 21 jan 2020];22(3):916-36. DOI: 10.1590/S0104-12902013000300023

23. Medeiros RD, Azevedo GD, Oliveira EAA, Araújo FA, Cavalcanti FJB, Araújo GL, Castro IR. Opinião de estudantes dos cursos de direito e medicina da Universidade Federal do Rio Grande do Norte sobre o aborto no Brasil. Rev Bras Ginecol Obstet [Internet]. 2012 [acesso 21 jan 2020];34(1):16-21. DOI: 10.1590/ S0100-72032012000100004 
24. Santana MVMC, Canêdo FMC, Vecchi AP. Anencefalia: conhecimento e opinião dos médicos ginecologistas-obstetras e pediatras de Goiânia. Rev. bioét. (Impr.) [Internet]. 2016 [acesso 21 jan 2020];24(2):374-85. DOI: 10.1590/1983-80422016242138

25. Faúndes A, Duarte GA, Andalaft Neto J, Olivatto AE, Simoneti RM. Conhecimento, opinião e conduta de ginecologistas e obstetras brasileiros sobre o aborto induzido. Rev Bras Ginecol Obstet [Internet]. 2004 [acesso 21 jan 2020];26(2):89-96. DOI: 10.1590/S0100-72032004000200002

26. Faúndes A, Duarte GA, Osis MJD, Andalaft Neto J. Variações no conhecimento e nas opiniões dos ginecologistas e obstetras brasileiros sobre o aborto legal, entre 2003 e 2005. Rev Bras Ginecol Obstet [Internet]. 2007 [acesso 21 jan 2020];29(4):192-9. DOI: 10.1590/S0100-72032007000400005

27. Benute GRG, Nonnenmacher D, Nomura RMY, Lucia MCS, Zugaib M. Influência da percepção dos profissionais quanto ao aborto provocado na atenção à saúde da mulher. Rev Bras Ginecol Obstet [Internet]. 2012 [acesso 21 jan 2020];34(2):69-73. DOI: 10.1590/S0100-72032012000200005

28. Darzé OISP, Azevêdo BKG. Competências adquiridas durante a formação médica e as opiniões e atitudes sobre o aborto. Rev Bras Ginecol Obstet [Internet]. 2014 [acesso 21 jan 2020];36(1):5-9. DOI: 10.1590/ S0100-72032014000100003

29. Madeiro A, Rufino A, Santos P, Bandeira G, Freitas I. Objeção de consciência e aborto legal: atitudes de estudantes de medicina. Rev Bras Educ Méd [Internet]. 2016 [acesso 21 jan 2020];40(1):86-92. DOI: 10.1590/1981-52712015v40n1e02382014

30. Universidade Federal da Bahia. Faculdade de Medicina da Bahia. Matriz curricular [Internet]. c2021 [acesso 7 mar 2021]. Disponível: https://bit.ly/2PTgBcp

Nathália Maria Fonseca Fróes - Graduanda - nathaliamfroes@gmail.com

(iD) 0000-0001-7681-4690

Cláudia Bacelar Batista - Doutora - claudia_bacelar@hotmail.com

(D) 0000-0003-1925-8813

Correspondência

Nathália Maria Fonseca Fróes - Rua da Paz, 53, Graça CEP 40150-140. Salvador/BA, Brasil.

Participação dos autores

Nathália Maria Fonseca Fróes delineou o estudo, coletou e analisou os dados e escreveu o artigo. Cláudia Bacelar Batista participou de todas as etapas como orientadora do trabalho de conclusão de curso que deu origem ao texto.

Recebido: 28.7 .2019

Revisado: 9.12 .2020

Aprovado: 3.2 .2021 


\section{Anexo}

\section{Questionário adaptado de Loureiro e Vieira ${ }^{20}$ e Rocha e colaboradores ${ }^{21}$}

\section{Características dos estudantes}

Idade:

( ) Até 18 anos

( ) De 19 a 22 anos

( ) De 23 a 26 anos

( ) De 27 a 30 anos

( ) Mais de 30 anos

Sexo:
( ) Feminino
( ) Masculino

Estado civil:

( ) Solteiro

( ) Casado

( ) União estável

Religião:

( ) Católica

( ) Umbanda

( ) Evangélica

( ) Budismo

( ) Espírita

( ) Agnóstico/ateu

( ) Matrizes africanas

( ) Testemunha de Jeová

( ) Sem religião

Renda familiar:

( ) Até 1,5 salário mínimo

( ) De 1,5 a 3 salários mínimos （） De 3 a 5 salários mínimos

( ) De 5 a 10 salários mínimos

( ) De 10 a 30 salários mínimos ( ) Mais de 30 salários mínimos

Cor:

( ) Branca ( ) Preta ( ) Parda ( ) Indígena ( )Amarela ( ) Outra

Semestre que está cursando:
( ) $1^{\circ}$ semestre
( ) $2^{\circ}$ semestre
( ) $3^{\circ}$ semestre
( ) $4^{\circ}$ semestre
( ) $5^{\circ}$ semestre
( ) $6^{\circ}$ semestre
( ) $7^{\circ}$ semestre
( ) $8^{\circ}$ semestre
( ) $9^{\circ}$ semestre
( ) $10^{\circ}$ semestre
( ) $11^{\circ}$ semestre
( ) $12^{\circ}$ semestre
( ) Não regular

\section{Conhecimentos gerais sobre aborto}

Com base em seus conhecimentos, marque "V" para verdadeiro e "F" para falso.

Nos países em desenvolvimento, o aborto é responsável por grande parte das mortes maternas.

O aborto repetido por dilatação e curetagem pode trazer riscos a uma futura gestação.

As mulheres que mais recorrem ao aborto provocado no Brasil costumam ter excedido o número desejado de filhos.

A maioria das mulheres que mais recorrem ao aborto provocado no Brasil é jovem.

$\mathrm{O}$ acesso eficiente ao planejamento familiar contribui para prevenir o aborto provocado.

O aborto é problema de saúde pública.

O acesso ao planejamento familiar promovido no Brasil é adequado.

O aborto não deve ser utilizado como método de planejamento familiar.

Conhecimento da legislação sobre abortamento
Com base em seus conhecimentos, marque "V" para verdadeiro e "F" para falso.
De acordo com o artigo 128 do Código Penal brasileiro e a decisão do Supremo Tribunal Federal de 2012, não se
pune o aborto praticado por médico quando (desconsiderar PEC 181/2015, ainda em tramitação):
A gestante corre risco de morte.
A gravidez resulta de estupro.

Continua... 


\section{Continuação}

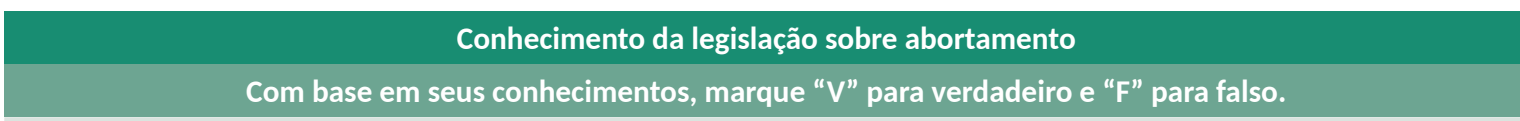

De acordo com o artigo 128 do Código Penal brasileiro e a decisão do Supremo Tribunal Federal de 2012, não se pune o aborto praticado por médico quando (desconsiderar PEC 181/2015, ainda em tramitação):

A gestante é menor de idade.

A mulher não deseja ter o filho.

Há risco para a saúde da gestante.

Em casos de feto com malformação cerebral incompatível com a vida extrauterina.

Para que seja realizado o abortamento legal:

É necessário boletim de ocorrência.

É necessário laudo do Instituto Médico Legal.

É necessário consentimento do marido.

Nenhum documento é necessário, apenas a palavra da mulher.

Quando há suspeita de abortamento ilegal, o médico:

Deve denunciar à polícia.

Não deve denunciar de modo algum.

Não pode denunciar, salvo por justa causa.

\section{A suspeita de abortamento ilegal deve ser anotada no prontuário?}

Sim, porque o registro é necessário à denúncia.

Não, porque é informação sigilosa.

Sim, porque o registro é necessário à correta condução do atendimento.

Sobre o direito à objeção de consciência:

Objeção de consciência é direito do profissional e pode ser alegado em qualquer ocasião.

O direito à objeção de consciência não cabe nos casos de necessidade de abortamento por risco de morte para a mulher.

O direito à objeção de consciência não cabe em situação de abortamento juridicamente permitido na ausência de outro(a) médico(a) que o faça.

O direito à objeção de consciência não cabe quando há complicações decorrentes de abortamento inseguro.

\begin{tabular}{l} 
Opiniões pessoais sobre o aborto \\
$\qquad$ Marque quantas opções forem necessárias. \\
\hline Quando você é favorável ao abortamento provocado? \\
Nunca \\
Estupro \\
Risco de morte \\
Risco à saúde \\
Malformação compatível com a vida \\
Malformação incompatível com a vida \\
A mulher não deseja ter o filho \\
Dificuldades socioeconômicas \\
Gravidez na adolescência
\end{tabular}

Continua... 


\section{Continuação}

\begin{tabular}{|c|}
\hline Opiniões pessoais sobre o aborto \\
\hline Marque quantas opções forem necessárias. \\
\hline Em sua opinião: \\
\hline A lei do aborto deve ser mudada. \\
\hline O aborto deve ser totalmente descriminalizado. \\
\hline Deveria haver ampliação dos casos permitidos por lei. \\
\hline Se fosse descriminalizado, praticaria profissionalmente. \\
\hline Os médicos que praticam aborto ilegal deveriam ser punidos. \\
\hline Denunciaria os médicos que praticam aborto ilegal. \\
\hline Considera crime recomendar medicamento abortivo mesmo sem prescrevê-lo. \\
\hline No futuro, como profissional, caso atenda um caso de aborto, você: \\
\hline Manterá o mínimo de contato necessário. \\
\hline Vai se aproximar ao máximo da mulher e esclarecê-la quanto às angústias da paciente. \\
\hline Sentirá raiva da mulher. \\
\hline Reprovará o ato da mulher. \\
\hline Acredita que a ilegalidade criará situações difíceis para os médicos. \\
\hline Quando o obstetra recebe um pedido de abortamento ilegal, ele deve: \\
\hline Atendê-la. \\
\hline Tentar reverter o desejo. \\
\hline Esclarecer o problema. \\
\hline Indicar outro médico. \\
\hline Indicar remédio abortivo. \\
\hline $\begin{array}{l}\text { Qual é a possibilidade de você atuar em serviço de referência para interrupção da gravidez em casos previstos em } \\
\text { lei ou em qualquer outro que envolva aborto? }\end{array}$ \\
\hline Não atuaria. \\
\hline Atuaria. \\
\hline Você acredita que os médicos que realizam abortamento legal devem ter qualificação específica? \\
\hline Sim \\
\hline Não \\
\hline Você tem conhecimento de qual é o centro de referência na cidade de Salvador/BA para abortamento legal? \\
\hline Sim \\
\hline Não \\
\hline
\end{tabular}

